\title{
Haze in the Klang Valley of Malaysia
}

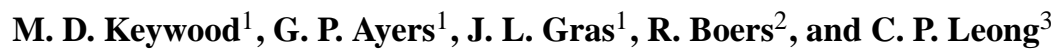 \\ ${ }^{1}$ CSIRO Atmospheric Research, Australia \\ ${ }^{2}$ Atmospheric Research Division KNMI Netherlands \\ ${ }^{3}$ Malaysian Meteorological Service, Malaysia
}

Received: 15 November 2002 - Published in Atmos. Chem. Phys. Discuss.: 10 February 2003

Revised: 27 May 2003 - Accepted: 27 May 2003 - Published: 5 June 2003

\begin{abstract}
Continuous measurements of dry aerosol light scattering (Bsp) were made at two sites in the Klang Valley of Malaysia between December 1998 and December 2000. In addition 24-hour PM2.5 samples were collected on a oneday-in-six cycle and the chemical composition of the aerosol was determined. Periods of excessive haze were defined as 24-hour average Bsp values greater than $150 \mathrm{Mm}^{-1}$ and these occurred on a number of occasions, between May and September 1999, during May 2000, and between July and September 2000. The evidence for smoke from biomass burning being a significant contributor to aerosol during periods of excessive haze is discussed. For example, during periods of excessive haze, the chemical composition of the aerosol showed enhanced concentrations of elemental carbon, organic carbon and non-seasalt potassium. The diurnal cycle of Bsp and PM10 was disturbed from its usual pattern of maxima overnight and minuma during the day with morning and afternoon traffic peaks, and instead showed a maximum peak during the middle of the day. Periods of excessive haze were coincident with the presence of forest fires on Sumatra during the southwest (SW) monsoon period, the influence of which are demonstrated by transport modelling for one week of the SW monsoon of 2000. The study highlights that whilst transboundary smoke is a major contributor to poor visibility in the Klang Valley, smoke from fires on Peninsular Malaysia is also a contributor. In addition the uniform concentration of non-seasalt sulfate in PM2.5 at both sites over the entire sampling period suggests the presence of a domestic source of secondary aerosol production in the Klang Valley.
\end{abstract}

\section{Introduction}

In recent times, reduced visibility has become a recurrent phenomenon across areas of Southeast Asia, resulting from

Correspondence to: M. D. Keywood

(melita.keywood@csiro.au) biomass burning in Kalimantan and Sumatra. Haze events have been recorded in 1983, 1990, 1991, 1994, 1997 and 1998 (Radojevic and Hassan 1999, Muraleedharan et al. 2000). Koe et al. (2001) noted that reduced visibility in Malaysia during the 1997 haze episode was the result of long range transport of smoke from Sumatra. Historically, major smoke hazes have been observed in the region, at times impeding shipping, as early as the 1800s (McDonald 1938). Episodes like the 1997 haze events prompt the need for a thorough understanding of the factors regulating the severity of haze in Kuala Lumpur (KL) and the surrounding Klang Valley region, including the source and transportation of particles.

While severe and disastrous, such events are episodic. Perhaps more insidious is the constant lower level of haze present in cities like KL where primary sources of particles such as vehicle emissions, industrial emissions and domestic biomass burning all contribute to haze. Secondary photochemical particle production can also be a major contributor to haze development. This occurs when gases from vehicle, industrial and biomass burning emissions undergo gas to particle conversion forming low vapour-pressure products that nucleate to form new particles, or condense on the surfaces of existing particles (Finlayson-Pitts and Pitts 2000).

Primary particles produced by combustion processes such as vehicle emissions, industrial emissions and domestic biomass burning and secondary photochemical production overwhelmingly result in particles in the fine particle range (i.e. less than $2.5 \mu \mathrm{m}$ in aerodynamic diameter). These particles are important in the development of haze because they are within the size range that scatters light most efficiently ( 0.1 to $1 \mu \mathrm{m}$ diameter). Particulate haze is a major environmental hazard. Besides impairing visibility, other potential problems associated with elevated particle loadings include impacts on human health (Vedal 1997) and impacts on atmospheric radiative transfer, with the potential to significantly affect climate in the region (Seinfeld and Pandis 1998). 


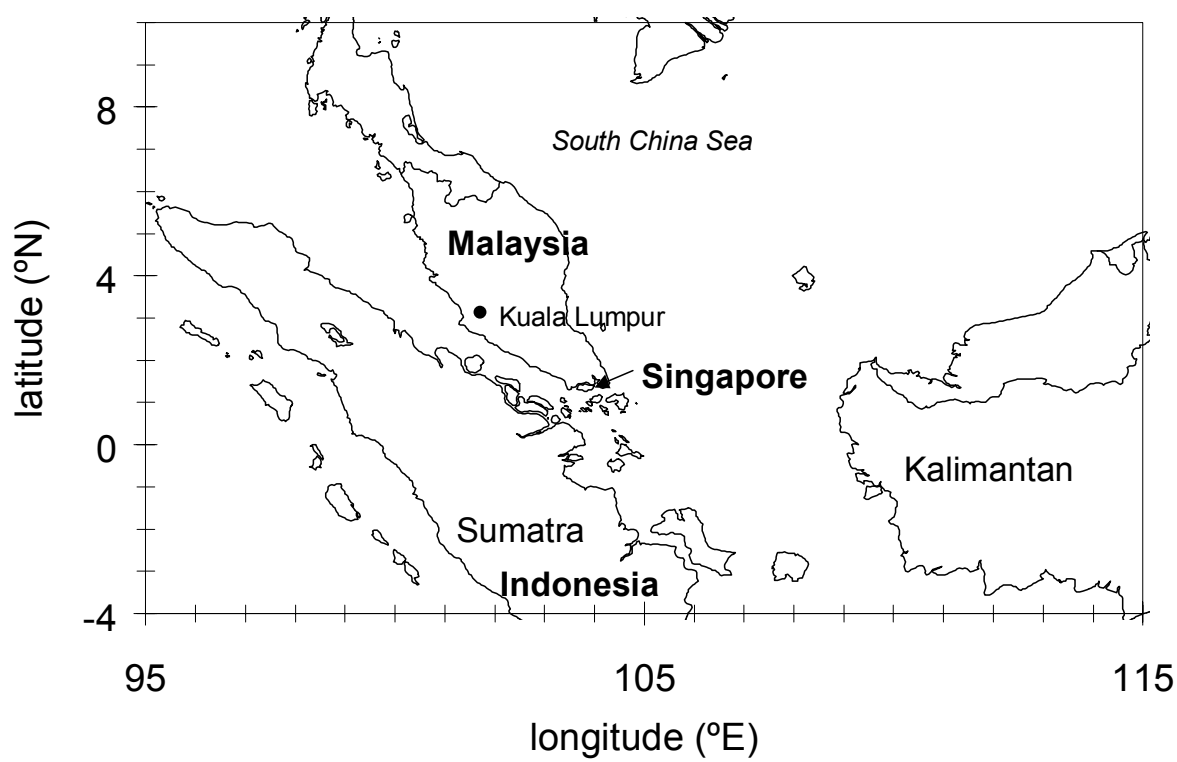

Fig. 1. Map of Peninsular Malaysia showing location of Kuala Lumpur. Gombak is located 12 km north of Kuala Lumpur and Petaling Jaya is located $7 \mathrm{~km}$ southwest of Kuala Lumpur.).

At present, knowledge of the factors regulating the severity of aerosol haze in KL and the surrounding Klang Valley region is incomplete. Two previous investigations into haze in Malaysia have focused on aerosol chemistry (JICA 1993 and NERI 1998), using the chemical composition of particles to determine the sources of haze. Neither study involved a direct measurement of haze intensity, for example aerosol scattering coefficient (Bsp). In the Malaysian Haze Study (MHS), a new study documented herein, the parameter Bsp was measured continuously over two years (December 1998 to December 2000) at two sites in the Klang Valley region to provide a real-time record of haze intensity. Bsp is the integrated aerosol light scattering coefficient, a direct measure of the reduction of light transmission through the atmosphere due to scattering by atmospheric particles. The previous studies also focused only on PM10 (particles smaller than $10 \mu \mathrm{m}$ in aerodynamic diameter) or SPM (suspended particulate matter or particles of all sizes), whereas the MHS set out to explain and find the fraction of the aerosol responsible for most visibility and health effects, i.e. PM2.5 (particles smaller than $2.5 \mu \mathrm{m}$ in aerodynamic diameter).

The MHS aimed to improve understanding of the haze phenomenon by investigation of the chemical composition, scattering coefficient and the mass concentrations of atmospheric particles at two sites in the Klang Valley region near KL (see Fig. 1). By combining information from the direct measurements of aerosol light scattering coefficient at both sites, and taking into account meteorological conditions throughout the measurement period, the MHS aimed to identify the sources of aerosol material and controlling meteorological factors on days of excessive haze.
This paper provides an overview of the MHS and focuses on the broad features of the aerosol scattering coefficients and aerosol composition over two years of measurements in the Klang Valley. The nearly complete continuous two-year record of hourly Bsp values, combined with the coincident two-year record of PM2.5 chemical composition, allows a unique analysis of haze development on seasonal and diurnal timescales. In this work, two major sources of particles, primary particles from biomass burning (smoke) and secondary production from domestic sources, are discussed in terms of their contribution to the seasonal and diurnal patterns of haze development.

\section{Methods}

\subsection{Measurement sites}

Aerosol measurements were carried out at two sites in the Klang Valley region: Petaling Jaya $\left(03^{\circ} 06^{\prime} \mathrm{N}, 101^{\circ} 39^{\prime} \mathrm{E}\right)$ and Gombak ( $\left.03^{\circ} 15.7^{\prime} \mathrm{N}, 101^{\circ} 39^{\prime} \mathrm{E}\right)$. The Petaling Jaya site, which is $7 \mathrm{~km}$ west of $\mathrm{KL}$, was situated on the rooftop of the Malaysian Meteorological Service (MMS) building $(\approx 18 \mathrm{~m}$ above the ground), alongside equipment operated by MMS. The closest building is $50 \mathrm{~m}$ to the southwest of the MMS building and is currently two levels higher. Petaling Jaya may be considered an urban/commercial area. During the course of the MHS, construction began on a large building $20 \mathrm{~m}$ to the west of the MMS building.

The Gombak site, which is $12 \mathrm{~km}$ north of Kuala Lumpur, was at the Department of Environment, Gombak air quality monitoring station operated by Alam Sekitar Malaysia 
Table 1. Description of the different types of filter media used, the analyses performed on each filter type and the preparation of filters

\begin{tabular}{cclc}
\hline TYPE & CODE & END-USE & PREPARATION \\
\hline Gelman stretched teflon & TEF & $\begin{array}{l}\text { Gravimetric mass, } \\
\text { soluble ions, } \\
\text { elemental carbon }\end{array}$ & Pre-weighed \\
Polycarbonate & PC & $\begin{array}{l}\text { Gravimetric mass, } \\
\text { insoluble elements, } \\
\text { elemental carbon } \\
\text { Total carbon }\end{array}$ & Pre-weighed \\
Quartz fibre & QF & Pre-baked $450^{\circ} \mathrm{C}$ for 24 hours \\
\hline
\end{tabular}

(ASMA). This is located in the grounds of the Gombak office of Jabatan Bekalan Air (Water Department, Gombak). The station is located in a valley at the edge of bordering highlands. The area surrounding the station is vegetation-covered and there are no tall buildings in the immediate vicinity of the station. The Gombak site may be considered semi-urban, bordering rural.

\subsection{Measurement methods}

Aerosol scattering coefficient, Bsp, at a wavelength of $530 \mathrm{~nm}$ was determined at each site using a Radiance Research M903 nephelometer. The nephelometer was operated with a heated inlet and heated chamber $\left(40^{\circ} \mathrm{C}\right)$ to minimise effects of hygroscopic growth on scattering of the aerosol, thus giving a measure of dry aerosol scattering coefficient. The resultant $\mathrm{RH}$ was $<5 \%$. Calibration of the nephelometer was performed using zero air and $\mathrm{CO}_{2}$ as a span gas. Automatic span and zero checks were carried out daily at Petaling Jaya and Gombak. In addition, weekly manual checks were carried out at Petaling Jaya for most of the sampling program and any drifts in the zero and spans are adjusted. At Gombak weekly manual calibration checks were carried out from December 1999. Where applicable, Bsp data were corrected for drift and offsets. All corrections were minor.

The aerosol samplers used in this study were Ecotech Dual Flow 1500 Aerosol Samplers. These samplers collect particles less than $2.5 \mu \mathrm{m}$ in aerodynamic diameter (PM2.5), collecting two samples in parallel on separate filters. Flow rate through the inlet was $16.71 \mathrm{~min}^{-1}$ with half the flow directed to each of the two filters. Filter media used for sample collection are described in Table 1. Three out of every four samples were collected on the combination of Teflon (TEF) and polycarbonate (PC) filters. One out of every four samples was collected on the combination of TEF and quartz fibre (QF) filters. Samples were collected for a 24-hour period on a one-day-in-six cycle, except during the July 2000 and September 2000 periods of excessive haze when daily samples were collected. TEF filters were used for the measurement of gravimetric mass and soluble ion concentrations, PC filters were used for the determination of gravimetric mass, elemental carbon and insoluble species concentration and QF filters were used to determine the concentration of total carbon.

Continuous PM10 concentrations were determined at Petaling Jaya and Gombak using a Beta Attenuation Gauge operated by ASMA.

\subsection{Analytical Methods}

TEF and PC filters were weighed using a Mettler UMT2 ultra-microbalance. Electrostatic charging was reduced by the presence of radioactive static discharge sources within the balance chamber. The balance was calibrated before each weighing session. The resolution of the balance is $0.0001 \mathrm{mg}(0.1 \mu \mathrm{g})$. Each filter was weighed repeatedly until three weights within $0.001 \mathrm{mg}$ were obtained. Before weighing, filters were dried in a desiccator for 24 hours at humidity of $\leq 20 \%$, and this humidity was maintained during the weighing procedure. The filters were weighed in this fashion both before and after exposure and the gravimetric mass determined as the difference between the two measurements. For the average masses measured for this work, uncertainties were $7 \%$ (at $95 \%$ confidence) for masses derived from TEF filters and $21 \%$ (at $95 \%$ confidence) for masses derived from PC filters.

Elemental carbon (EC) was determined by light absorption using the integrated plate method modified from Lin et al. (1973). The system was calibrated for elemental carbon using an aerosol produced by pyrolysis of acetylene (Gras 1996), which yielded a specific mass absorption of $10.4 \mathrm{~m}^{2} \mathrm{~kg}^{-1}$. The reproducibility of the EC measurement was $\pm 10 \%$ (at $95 \%$ confidence).

Total carbon (TC) was determined from the samples collected on the QF filters. A sample and blank was determined for each sample. The blank concentration was determined from a second quartz filter placed in series behind the sample filter in a single filter holder and was on average $5 \%$ of the sample. TC was determined using thermal decomposition to $\mathrm{CO}_{2}$ in $\mathrm{CO}_{2}$-free air in a tube furnace at $850^{\circ} \mathrm{C}$, with a copper catalyst to oxidise any $\mathrm{CO}$ formed by partial oxidation. A Licor 6262 analyser was used to determine the evolved $\mathrm{CO}_{2}$. The carbon analyser was calibrated by injection of known quantities of $\mathrm{CO}_{2}$ into the flowing air stream. The 

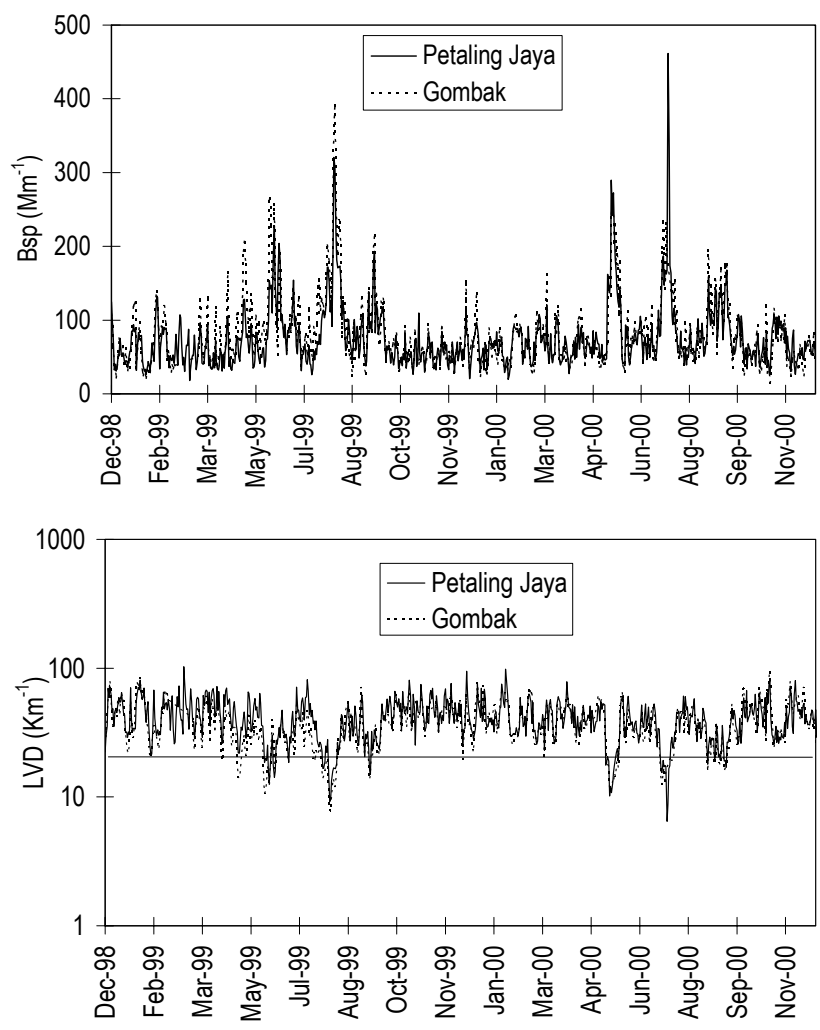

Fig. 2. Time series of daily Bsp and LVD (24-hour averages) at Petaling Jaya and Gombak. LVD of $20 \mathrm{~km}$ is marked for reference.

reproducibility of the TC measurement was $\pm 15 \%$ (at $95 \%$ confidence).

Ion chromatography (IC) was used to measure soluble ions in aqueous extracts of the samples collected on the TEF filters. Ions determined were: $\mathrm{Na}^{+}, \mathrm{NH}_{4}^{+}, \mathrm{K}^{+}, \mathrm{Mg}^{2+}, \mathrm{Ca}^{2+}$, $\mathrm{Cl}^{-}, \mathrm{NO}_{3}^{-}, \mathrm{SO}_{4}^{2-}, \mathrm{Br}^{-}, \mathrm{NO}_{2}^{-}, \mathrm{PO}_{4}^{3-}, \mathrm{F}^{-}$, acetate, formate, oxalate and methanesulfonic acid (MSA). The substrates were wetted with methanol before being extracted in $12 \mathrm{ml}$ of Milli-Q HPLC grade (high purity de-ionised) water, and a bactericide (120 $\mu \mathrm{l}$ of chloroform) was added to preserve the extracted sample from biological degradation. The ionic concentrations were determined using a Dionex DX500 gradient ion chromatograph employing Dionex IC columns, an AS11 column and ARS1 suppressor for anions, a CS12 column and CRS1 suppressor for the cations. Quality control assessment procedures for the IC measurements included measurement of duplicates, and ionic balances and comparison of calculated and measured conductivity compliance to USEPA criteria (USEPA 1994).

Proton induced $\mathrm{x}$-ray emission (PIXE) was used to determine concentration of elements including $\mathrm{Na}, \mathrm{Al}, \mathrm{Si}, \mathrm{P}, \mathrm{S}$, $\mathrm{Cl}, \mathrm{K}, \mathrm{Ca}, \mathrm{Ti}, \mathrm{V}, \mathrm{Cr}, \mathrm{Mn}, \mathrm{Fe}, \mathrm{Cu}, \mathrm{Co}, \mathrm{Ni}, \mathrm{Zn}, \mathrm{Br}$ and $\mathrm{Pb}$. PIXE analyses were conducted by the Australian Science and Technology Organisation (ANSTO) and involved bombarding the sample with $2.6 \mathrm{MeV}$ proton beams. An 8-mm di- ameter beam with an incident proton charge of $3 \mu \mathrm{C}$ is used to bombard the sample. Comparability of the two chemical datasets was assessed by comparison of $\mathrm{S}$ determined by PIXE and $\mathrm{SO}_{4}^{2-}$ determined by IC.

\subsection{Modelling The Air Pollution Model (TAPM)}

Modelling was carried out using the CSIRO coupled meteorological and air pollution model, TAPM (Hurley 1999). TAPM uses databases of terrain, vegetation, soil types, seasurface temperature and synoptic-scale meteorological analyses to derive the meteorological component. The pollution component is derived using point source emission data or gridded emission inventories of air pollutants. In this work, TAPM was run with three $40 \times 40$ nested grids with spacings of $30 \mathrm{~km}, 10 \mathrm{~km}$ and $3 \mathrm{~km}$ (i.e. domains of $1200 \times 1200 \mathrm{~km}$, $400 \times 400 \mathrm{~km}$ and $120 \times 120 \mathrm{~km}$ ), centred on Petaling Jaya. TAPM was used to simulate the transboundary transport of smoke to the Klang Valley and the diurnal cycle of PM10 at Petaling Jaya.

\section{Observations}

\subsection{Aerosol scattering coefficient}

Time series of daily-averaged Bsp and local visual distance (LVD) at Petaling Jaya and Gombak are shown in Fig. 2. LVD is a measure of visual range usually defined as the distance at which a black object can be distinguished against the horizon. LVD therefore depends upon contrast and visual sharpness, and is related to the volume extinction coefficient Be by the Koschmeider relationship (Griffing 1980), where $\mathrm{A}$ is the Koschmeider constant and

$\mathrm{LVD}=\mathrm{A} / \mathrm{B}_{\mathrm{e}}$

The extinction coefficient $\mathrm{B}_{\mathrm{e}}$ is approximated by the dry scattering coefficient Bsp and the molecular scattering coefficient of atmospheric gases. LVD is only an approximation to actual visual range because Bsp is measured at a point, rather than integrated over an atmospheric light path, and Bsp is the measured scattering efficiency of dry aerosol particles, not the aerosol droplet population that typically results at ambient humidity. In addition aerosol absorption will contribute to $B_{e}$. While this study did not involve a continuous measurement for absorption, the EC measurements were used to correct LVD for the effect of aerosol absorption

In this work we define excessive haze as occurring when LVD falls below $20 \mathrm{~km}$ for a one-hour period. This translates to a Bsp value of greater than $180 \mathrm{Mm}^{-1}$ over one hour. An average Bsp over 24 hours for days of excessive haze was determined by calculating the 24-hour average Bsp on days when at least one hour displayed LVD of lower than $20 \mathrm{~km}$. Thus the average Bsp on days of excessive haze was calculated to be greater than $150 \mathrm{Mm}^{-1}$ over 24-hours, over the 

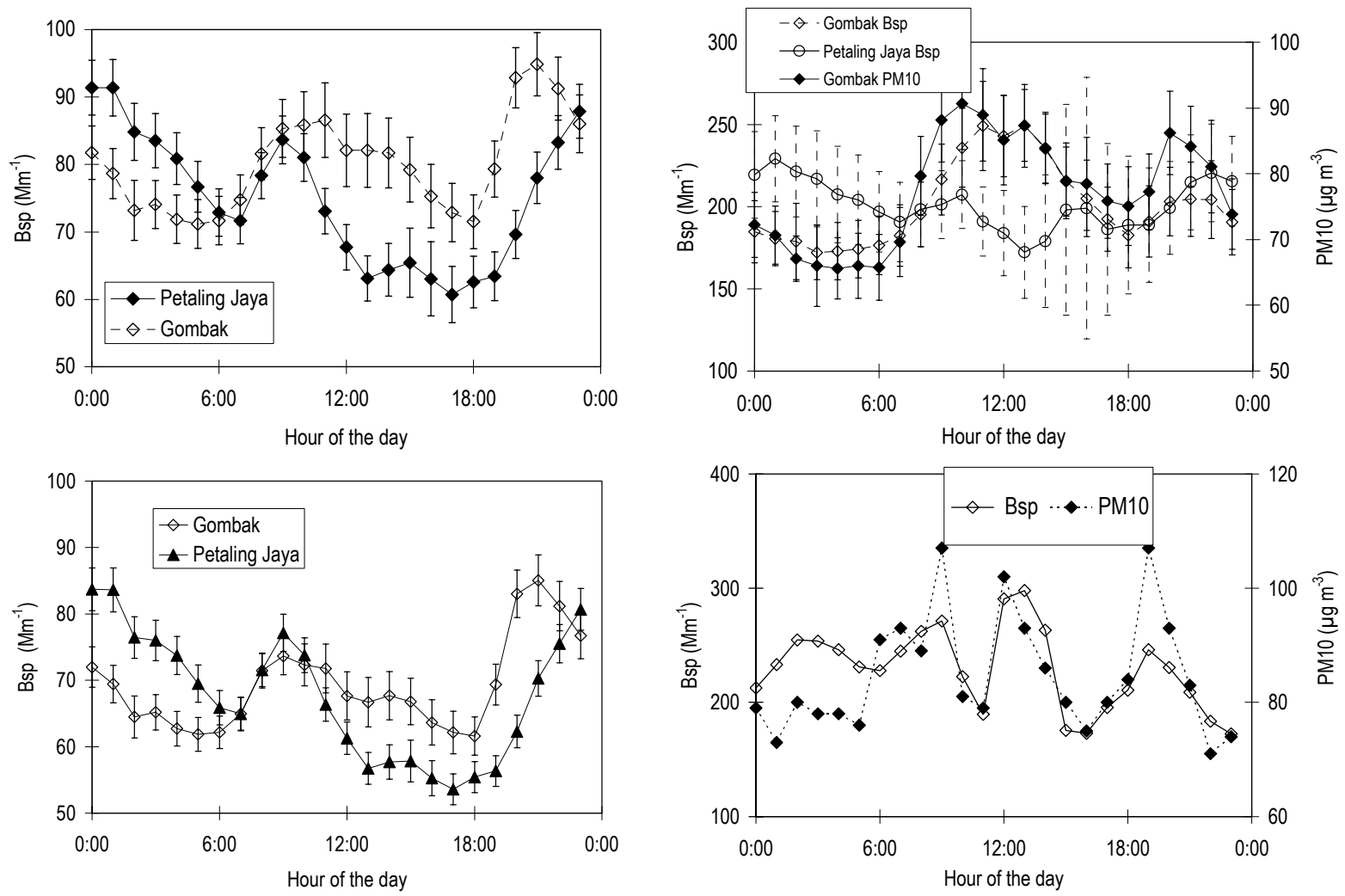

Fig. 3. Plots of (a) average diurnal pattern for all Bsp data at Petaling Jaya and Gombak, (b) average diurnal pattern of Bsp and PM10 at Gombak and Bsp at Petaling Jaya for days when average Bsp $>150 \mathrm{Mm}^{-1}$, (c) average diurnal pattern of Bsp at Petaling Jaya and Gombak for days with average Bsp $<150 \mathrm{Mm}^{-1}$, (d) diurnal pattern of Bsp and PM10 at Petaling Jaya and Gombak on 13 July 2000.

same interval for which aerosol chemical data (PM2.5 samples) were averaged.

The broad temporal variation in Bsp over the two-year measurement period was essentially the same at both sites, with excessive levels of aerosol scattering occurring between May and September 1999, during May 2000, and between July and September 2000.

Figure 3a shows the average diurnal pattern of Bsp at Petaling Jaya and Gombak. This pattern is a maximum Bsp overnight, decreasing through the early hours of the morning and increasing between 07:00 and 11:00. This increase is followed by a gradual decrease throughout the early afternoon and a sharp increase after about 18:00. Bsp continues to increase until midnight. This generalised pattern can be attributed to the diurnal changes in the source of particles (i.e. traffic peaks in the morning and late afternoon). In addition, mixing processes in the planetary boundary layer vent surface emissions to higher levels during the day, so diluting pollutants. However, at night pollutants are trapped in a shallow (near-surface) nocturnal boundary layer. Similar patterns in other cities have been reported, for example, by Cohen et al. (1997) for Jakarta.

Figure 3 also shows the diurnal patterns of Bsp and PM10 at Gombak when the Bsp data are selected for days with daily average Bsp greater than $150 \mathrm{Mm}^{-1}$ (Fig. 3b). The number of days with average Bsp greater than $150 \mathrm{Mm}^{-1}$ was $8 \%$ of the total number of days measured at Gombak. On these days the diurnal pattern shows a broad peak during the middle of the day. The diurnal patterns for Bsp when the daily average Bsp was lower than $150 \mathrm{Mm}^{-1}$ for Gombak and Petaling Jaya are shown in Fig. 3c. These patterns of variation are similar to the average diurnal patterns displayed by all data (Fig. 3a). Also shown in Fig. 3b is the diurnal pattern for Bsp at Petaling Jaya for days when the daily average Bsp is greater than $150 \mathrm{Mm}^{-1}$ (accounting for 5 of days). The pattern of variation is similar to the pattern displayed for days with Bsp less than $150 \mathrm{Mm}^{-1}$, except that a peak occurs during the middle of the afternoon (matched by a trough in the patterns for days less than $150 \mathrm{Mm}^{-1}$ ).

The diurnal plots in Fig. 3 reveal two patterns of variation, the first is the normal pattern with maximum Bsp (and PM10) overnight and minima during the day with peaks during the morning and afternoon traffic peaks (Figs. 3a and 3c). The second pattern is for a minimum overnight and peaks during the middle of the day (Fig. 3b). This behaviour is distinctly displayed by PM10 and Bsp at Gombak on days of elevated scattering and less distinctly displayed at Petaling Jaya where a small peak is observed in the middle of the 


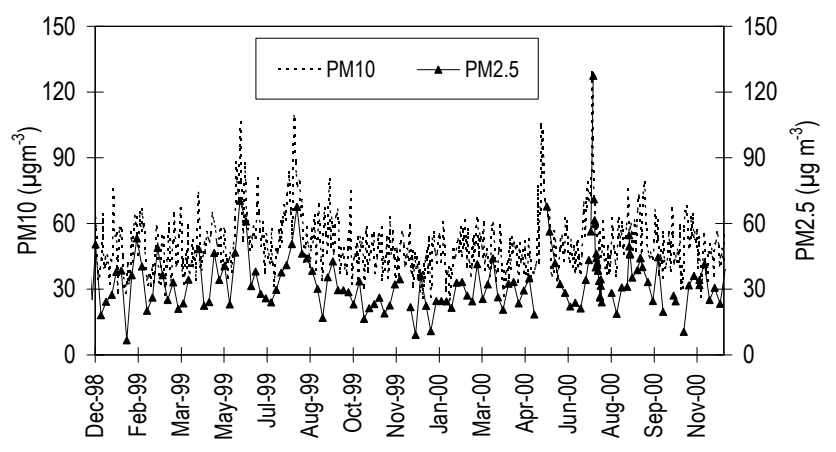

Fig. 4. Time series of PM10 (Beta-Gauge 24-hour averages) and PM2.5 (all sampled for 24 hours on a one-day-in-six cycle) at Petaling Jaya.

afternoon. Figure 3d displays the diurnal pattern for Bsp and PM10 at Gombak for a single day when the average Bsp was greater than $150 \mathrm{Mm}^{-1}$ (13 July 2000). A peak in the Bsp and PM10 record is evident at both sites between 12:00 and 14:00, as well as at other times.

\subsection{Aerosol mass}

The time series of daily averaged PM10 measured at Petaling Jaya using a Beta Gauge is shown in Fig. 4. Also shown is the time series of PM2.5 determined from aerosol samples collected over a 24-hour period on a one-day-in-six cycle, except between 16 and 25 July and 24 and 30 August 2000 when samples were collected on a daily basis. Elevated PM10 and PM2.5 levels occur between May and September 1999, during May 2000, and between July and September 2000. A similar pattern of PM10 and PM2.5 variation was observed at Gombak.

\subsection{Aerosol Chemistry}

Figure 5 displays plots of the relationships between various chemical species measured in the PM2.5 aerosol samples. The evident structural relationships between these species illustrate characteristic "chemical fingerprints" of different sources.

Figure 5a displays the relationship between $\mathrm{Na}^{+}$and $\mathrm{Mg}^{2+}$ and Fig. 5 b the relationship between $\mathrm{Si}$ and $\mathrm{Al}$ along with the known ratios of these species in seawater (Millero 1974) and crustal rocks (Mason and More 1982). The similarity between the ratios of these species measured in the aerosol samples, and the ratios measured in seawater and crustal rocks, suggests that $\mathrm{Na}^{+}$and $\mathrm{Mg}^{2+}$ are appropriate tracers for sea-salt and $\mathrm{Si}$ and $\mathrm{Al}$ are tracers for soil-dust.

Figure 5c displays the relationship between $\mathrm{NH}_{4}^{+}$and $\mathrm{nssSO}_{4}^{2-}$. $\mathrm{NssSO}_{4}^{2-}$ represents non-sea-salt $\mathrm{SO}_{4}^{2-}$ (i.e. all $\mathrm{SO}_{4}^{2-}$ that is derived from particles other than sea-salt). $\mathrm{NssSO}_{4}^{2-}$ was calculated by assuming that all $\mathrm{Na}^{+}$present was of sea-salt origin, enabling sea-salt $\mathrm{SO}_{4}^{2-}$ to be calculated from the known ratio of $\mathrm{Na}^{+}$to $\mathrm{SO}_{4}^{2-}$ in seawater. The strong relationship between these species arises from the neutralisation of $\mathrm{SO}_{4}^{2-}$ (produced by oxidation of $\mathrm{SO} 2$ ) by $\mathrm{NH}_{4}^{+}$, and reflects the stoichiometry of this relationship. This suggests a secondary production source for the aerosol via photochemical oxidation of $\mathrm{SO}_{2}$ to $\mathrm{SO}_{4}^{2-}$ in the atmosphere followed by uptake of $\mathrm{NH}_{3}$, which is ubiquitous in the atmosphere.

Figure $5 \mathrm{~d}$ displays the relationship between $\mathrm{nssK}^{+}$and EOM. NssK ${ }^{+}$is non sea-salt $\mathrm{K}^{+}$and is calculated in analogous fashion to the calculation of $\mathrm{nssSO}_{4}^{2-}$, in this case using the ratio of $\mathrm{Na}^{+}$to $\mathrm{K}^{+}$in seawater. $\mathrm{NssK}^{+}$is a significant component of two major particle sources, soil dust and vegetation. EOM is an estimate of organic mass and is calculated from the difference between gravimetric mass (GM), and the sum of elemental carbon (EC) and inorganic mass (IM), where IM is calculated as described in Brook et al. (1997), see Sect. 3.4 for details. The evident structural relationship between $n s s \mathrm{~K}^{+}$and EOM in Fig. 5d suggests a significant biomass-burning source for PM2.5 aerosol material at both Petaling Jaya and Gombak, since there is minimal organic matter in soil dust.

Time series for some of these chemical marker species are shown in Fig. 6. The time series for $\mathrm{Na}^{+}$at Gombak and $\mathrm{Si}$ at Petaling Jaya are displayed in Fig. 6a. Note that the time series of $\mathrm{Na}^{+}$at Petaling Jaya is similar to that seen at Gombak in Fig. 6a and the time series of $\mathrm{Si}$ at Gombak is similar to that displayed at Petaling Jaya in Fig. 6a. A peak in $\mathrm{Na}^{+}$ concentrations during January and February 2000 suggests an influx of sea-salt aerosol during this time. A possible influx of soil-dust occurring during May 1999 is shown in the Si time series, with a peak in Si concentration at Petaling Jaya in August 2000 most likely representing localised building activity, particularly the construction of a building adjacent to the Petaling Jaya sampling site.

Figure $6 \mathrm{~b}$ shows the time series plot of $\mathrm{nssK}^{+}$at Gombak and EOM at Petaling Jaya. Again note that the time series of $\mathrm{nssK}^{+}$displayed at Petaling Jaya is similar to that shown by Gombak in Fig. 6b and the time series for EOM at Gombak is similar to that displayed by Petaling Jaya shown in Fig. $6 \mathrm{~b}$. EOM and $\mathrm{nssK}^{+}$display elevations during May 1999 and August 1999 and June to August 2000. This pattern suggests an influx of biomass burning aerosol, or smoke, during these times, which are coincident with periods of excessive haze, defined in Sect. 4.2.

Figure $6 \mathrm{c}$ displays the time series plots of $\mathrm{nssSO}_{4}^{2-}$ at both sites. Again, a similar pattern of variation is observed at both sites. The relatively uniform amplitude fluctuation through the year is consistent with a major local source such as secondary production. 

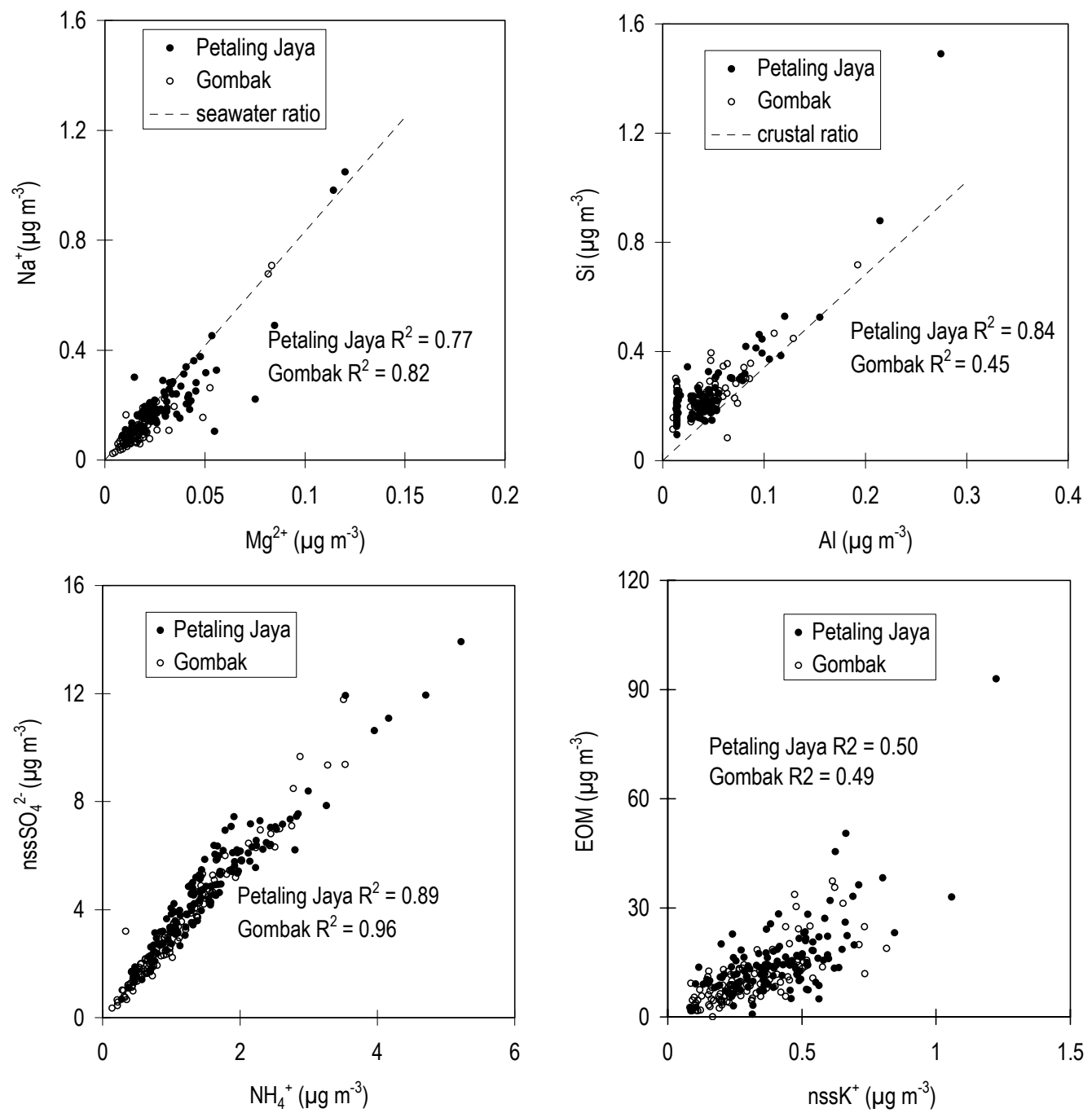

Fig. 5. Relationships between (a) $\mathrm{Na}^{+}$and $\mathrm{Mg}^{2+}$, (b) $\mathrm{Si}$ and $\mathrm{Al}$ (c) $\mathrm{NH}_{4}^{+}$and nssSO ${ }_{4}^{2-}$ and (d) $\mathrm{nssK}^{+}$and EOM in $\mathrm{PM}_{2.5}$ aerosol samples collected at Petaling Jaya and Gombak over 24-hour periods. The ratios of $\mathrm{Na}^{+}$to $\mathrm{Mg}^{2+}$ in seawater (Millero, 1974), and Si to $\mathrm{Al}$ in the earth's crust (Mason and Moore, 1982) are also plotted.

\subsection{Mass Balance}

In this work, an attempt was made to measure as many chemical species as was practically possible. The chemical composition of aerosol can be divided into major and trace species, and there should be a balance between the mass of aerosol determined and the sum of all chemical constituents. Besides gravimetric mass (GM), the major species determined in this work were inorganic mass (IM), determined from the sum of all soluble and insoluble inorganic species according to Brook et al. (1997), elemental carbon (EC) and organic carbon (OC), where

$\mathrm{GM}=\mathrm{IM}+\mathrm{EC}+\mathrm{OC}$.
OC was determined by two methods: firstly, it was directly measured as total carbon on the QF filters and the EC subtracted according to

$\mathrm{TC}=\mathrm{OC}+\mathrm{EC}$

Secondly, EOM was estimated using the difference between the total mass and chemical constituents according to

$\mathrm{EOM}=\mathrm{GM}-\mathrm{EC}-\mathrm{IM}$

A comparison of the EOM and measured OC for 24 samples is shown in Fig. 7. The figure displays scatter consistent with the expected measurement uncertainties (reproducibility $\pm 15 \%$ and blank measurements $\pm 5 \%$ ). This diagram confirms that the EOM is a good surrogate for OC and is used in the following discussion to represent OC. 
Table 2. Comparison of relative proportions of major chemical species for days of excessive haze and other days (normal) at Petaling Jaya and Gombak

\begin{tabular}{|c|c|c|c|c|c|}
\hline Species & & $\begin{array}{l}\text { PETALING JAYA } \\
\text { Excessive haze }\end{array}$ & Normal & $\begin{array}{c}\text { GOMBAK } \\
\text { Excessive haze }\end{array}$ & Normal \\
\hline EOM & $\%$ of GM & 61 & 42 & 56 & 37 \\
\hline $\mathrm{EC}$ & & 20 & 30 & 25 & 38 \\
\hline IM & & 19 & 28 & 19 & 25 \\
\hline sulfate & $\%$ of IM & 43 & 51 & 58 & 56 \\
\hline ammonium & & 16 & 16 & 19 & 18 \\
\hline oxalate & & 6 & 4 & 5 & 3 \\
\hline K & & 6 & 5 & 6 & 5 \\
\hline $\mathrm{Si}$ & & 4 & 3 & 3 & 4 \\
\hline $\mathrm{Na}$ & & 2 & 2 & 1 & 2 \\
\hline
\end{tabular}

Table 3. Descriptive summary of seasonal wind patterns in Malaysia

\begin{tabular}{|c|c|c|}
\hline SEASON & DATES(FROM MMS 1999) & CHARACTERISTICS \\
\hline Inter-monsoon (Int1) & 15 Mar. to 14 May & $\begin{array}{l}\text { Light variable winds when an equatorial } \\
\text { trough lies over Malaysia }\end{array}$ \\
\hline Southwest monsoon (SW) & 15 May to 14 Sept. & $\begin{array}{l}\text { Southwesterly winds below } 8 \mathrm{~m} \mathrm{~s}^{-1} \text {. } \\
\text { Sabah and Sarawak may experience winds of } \\
10 \mathrm{~m} \mathrm{~s}^{-1} \text { when typhoons develop over the } \\
\text { west Pacific and move westwards across the Philippines }\end{array}$ \\
\hline Inter-monsoon (Int 2) & 15 Sept. to 30 Oct. & $\begin{array}{l}\text { Light variable winds when equatorial } \\
\text { trough lies over Malaysia }\end{array}$ \\
\hline Northeast monsoon (NE) & 1 Nov. to 14 Mar. & $\begin{array}{l}\text { Easterly to northeasterly winds } 5 \text { to } 10 \mathrm{~m} \mathrm{~s}^{-1} \text {. } \\
\text { East coast states of Peninsular Malaysia may experience }\end{array}$ \\
\hline winds of $15 \mathrm{~m} \mathrm{~s}^{-1}$ during cold surges from the north & & \\
\hline
\end{tabular}

The average composition of the major chemical components of the aerosol is shown in Fig. 8. At Petaling Jaya, EOM is the major constituent, with EC and IM being approximately equal. Of the IM, sulfate, ammonium, $\mathrm{K}$ and oxalate are the most significant species (Fig. 8a). A similar picture is seen for Gombak (Fig. 8b).

Note that $\mathrm{nssSO}_{4}^{2-}$ makes up $98 \%$ of sulfate and $\mathrm{nssK}^{+}$ makes up $98 \%$ of $\mathrm{K}$. This is because the aerosol samples collected were the PM2.5 size fraction, therefore excluding particles greater than $2.5 \mu \mathrm{m}$ in aerodynamic diameter, the size range in which most sea-salt sulfate, sea-salt $\mathrm{K}$ and soil-dust $\mathrm{K}$ predominately occur. Thus in the following discussion, sulfate and $\mathrm{K}$ are used instead of $\mathrm{nssSO}_{4}^{2-}$ and $\mathrm{nssK}^{+}$. Also, note that oxalate is an organic acid associated with biomass burning. Oxalic acid is produced from the combustion of the cellulose material in vegetation (Gao et al. 2003).

\section{Discussion}

The observations of the temporal and diurnal patterns of Bsp, PM10 and PM2.5 chemical composition, along with the chemical relationships described above, allow us to make qualitative suggestions about the sources of aerosol to Petaling Jaya and Gombak. Smoke from biomass burning is clearly a very important and at times the dominant source of aerosol at each site, as displayed by the predominance of EOM (Fig. 8) and its association with K. Sulfate makes up $50 \%$ of IM, indicating the potential importance of secondary production at both Petaling Jaya and Gombak. $\mathrm{Na}^{+}$and $\mathrm{Si}$ are both minor components of IM, indicating that sea-salt and soil-dust are insignificant sources of PM2.5 aerosol.

An early study of aerosol in KL by JICA (1993) gives a comprehensive assessment of air quality issues and consequences in the Klang Valley region. One small component of that study was a source apportionment analysis applied to a limited number of SPM samples. This source apportionment differentiated various sources contributing to the atmospheric haze, including soil-dust, sea-salt, industry, woodsmoke, secondary particle production and diesel and petrol combustion. Interestingly, a later study by NERI (1998) could not identify a vehicle source of particles at Petaling Jaya using source apportionment analysis, despite noting that the diurnal pattern in PM10 variation showed evidence of a contribution by traffic throughout the day. 

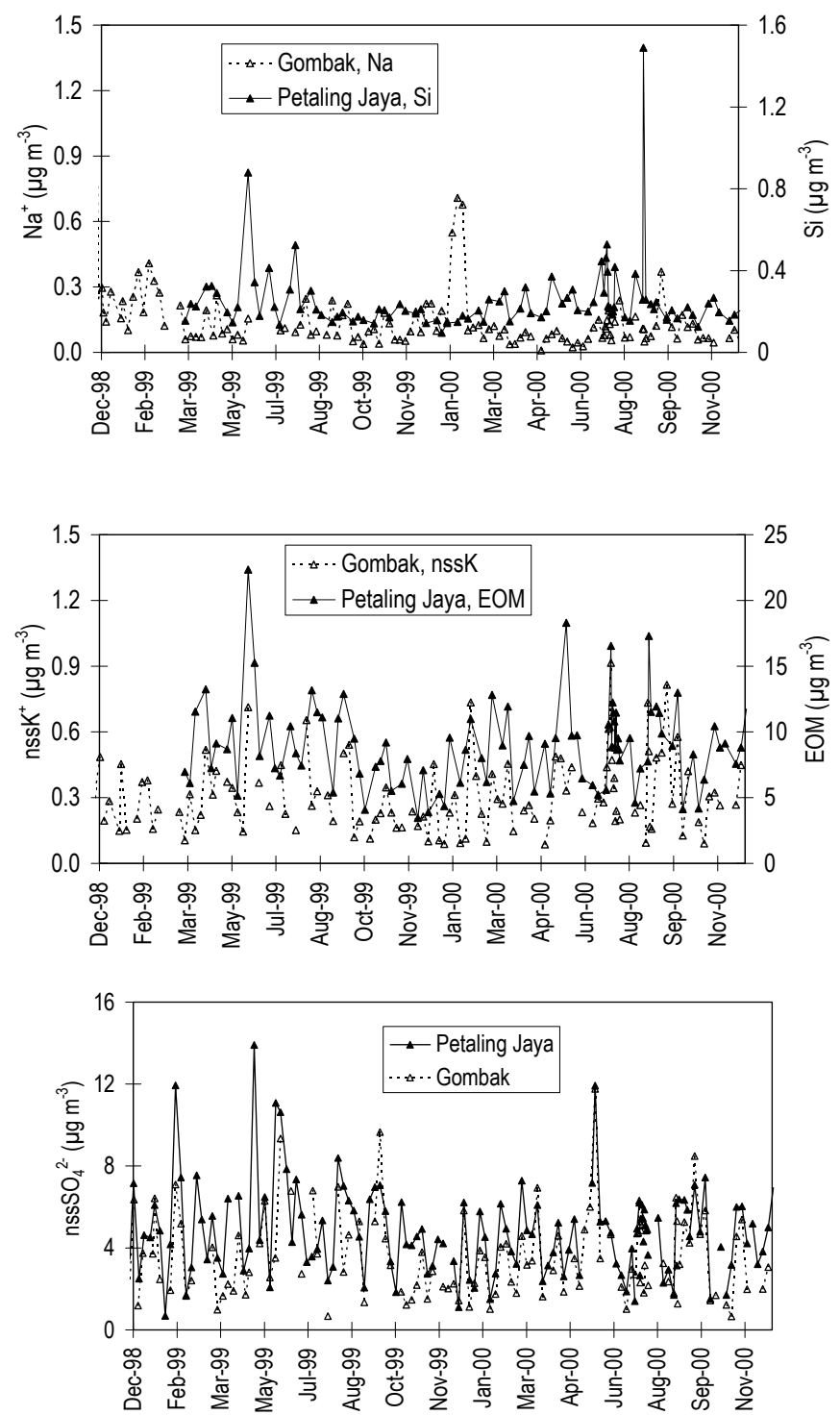

Fig. 6. Time series of (a) $\mathrm{Na}^{+}$at Gombak and $\mathrm{Si}$ at Petaling Jaya (b) $\mathrm{nssK}^{+}$at Gombak and EOM at Petaling Jaya and (c) $\mathrm{nssSO}_{4}^{2-}$ at both sites measured in 24-hour PM2.5 aerosol samples.

We have not identified a vehicle emissions source in our qualitative description of the variations in aerosol chemistry, because of the lack of a suitable tracer for vehicle emissions in our chemical analysis of the PM2.5 aerosol samples. Previously, variations in $\mathrm{Pb}$ and $\mathrm{Br}$ have been useful tracers for vehicle emissions; however, $\mathrm{Pb}$ has been removed from petrol in Malaysia since January 1999. Nethertheless, we believe that a detailed source apportionment analysis utilising other tracers for vehicle emissions such as $\mathrm{NO}$ and $\mathrm{CO}$ will result in identification of this source in the Klang Valley. A detailed source apportionment study will be reported elsewhere.

Days of excessive haze have been defined for this work as 24-hour average Bsp greater than $150 \mathrm{Mm}^{-1}$. At Petaling

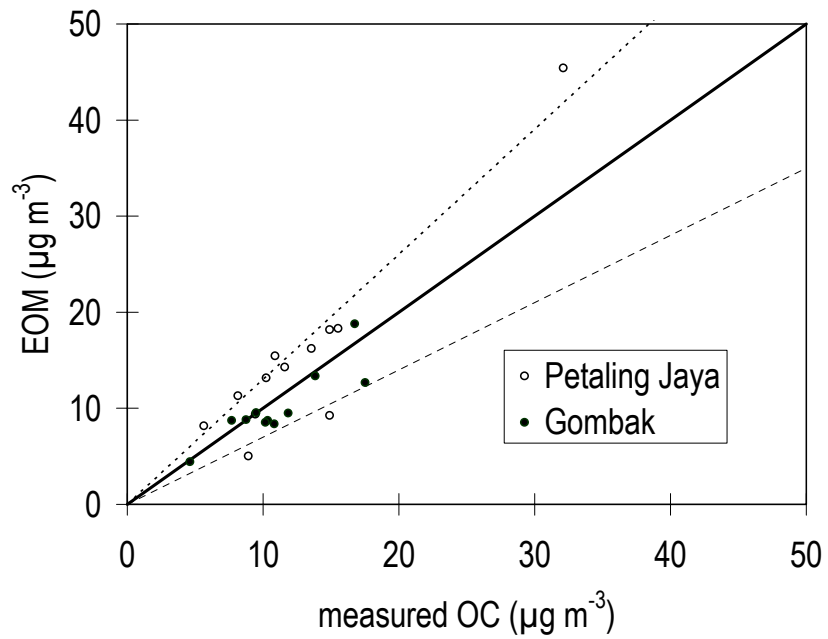

Fig. 7. Comparison of EOM and measured OC. The dotted lines represent the range expected due to reproducibility of the TC measurement $(15 \%)$ and the blank determinations $(5 \%)$.

Jaya this occurred on 5\% of days (9 days of which PM2.5 samples were collected) and at Gombak on $8 \%$ of days (10 days of which PM2.5 samples were collected). Table 2 compares the relative proportions of each of the major species and components of IM for days of excessive haze and for days of non-excessive haze. At both sites, on days of excessive haze EOM is a larger component than on the lowhaze days. This is matched by an increase in potassium $(\mathrm{K})$ and oxalate, suggesting that on days of excessive haze, smoke from biomass burning makes a larger contribution to the aerosol at both sites.

The variation displayed by $\mathrm{SO}_{4}^{2-}$ on days of excessive haze (Fig. 6c) is not always consistent between Petaling Jaya and Gombak, suggesting that the secondary source of aerosol for which we use $\mathrm{SO}_{4}^{2-}$ as a surrogate is not dependent on a smoke source. This follows since secondary production is the result of photochemical oxidation of $\mathrm{SO}_{2}$ to $\mathrm{SO}_{4}^{2-}$, so that any source of $\mathrm{SO}_{2}$ will influence the strength of secondary particle production. Mannins (1994) suggests that industry and the Port Klang Power Station are the dominant sources of $\mathrm{SO}_{2}$ in the Klang Valley and that vehicle emissions are insignificant. In 1994 the sulfur content of diesel in Malaysia was $0.5 \% . \mathrm{Na}^{+}$and $\mathrm{Si}$ are both minor components of IM, indicating, as expected, that sea-salt and soil-dust are insignificant sources of PM2.5 aerosol.

\subsection{Smoke from biomass burning- seasonal variations}

The chemical composition of PM2.5 aerosol suggests that smoke is a major source of particles contributing to haze in the Klang Valley. In this section the variations in haze as a function of season are analysed. The four seasons in Malaysia are the southwest monsoon, northeast monsoon and two shorter inter-monsoon seasons (Table 3), and are 

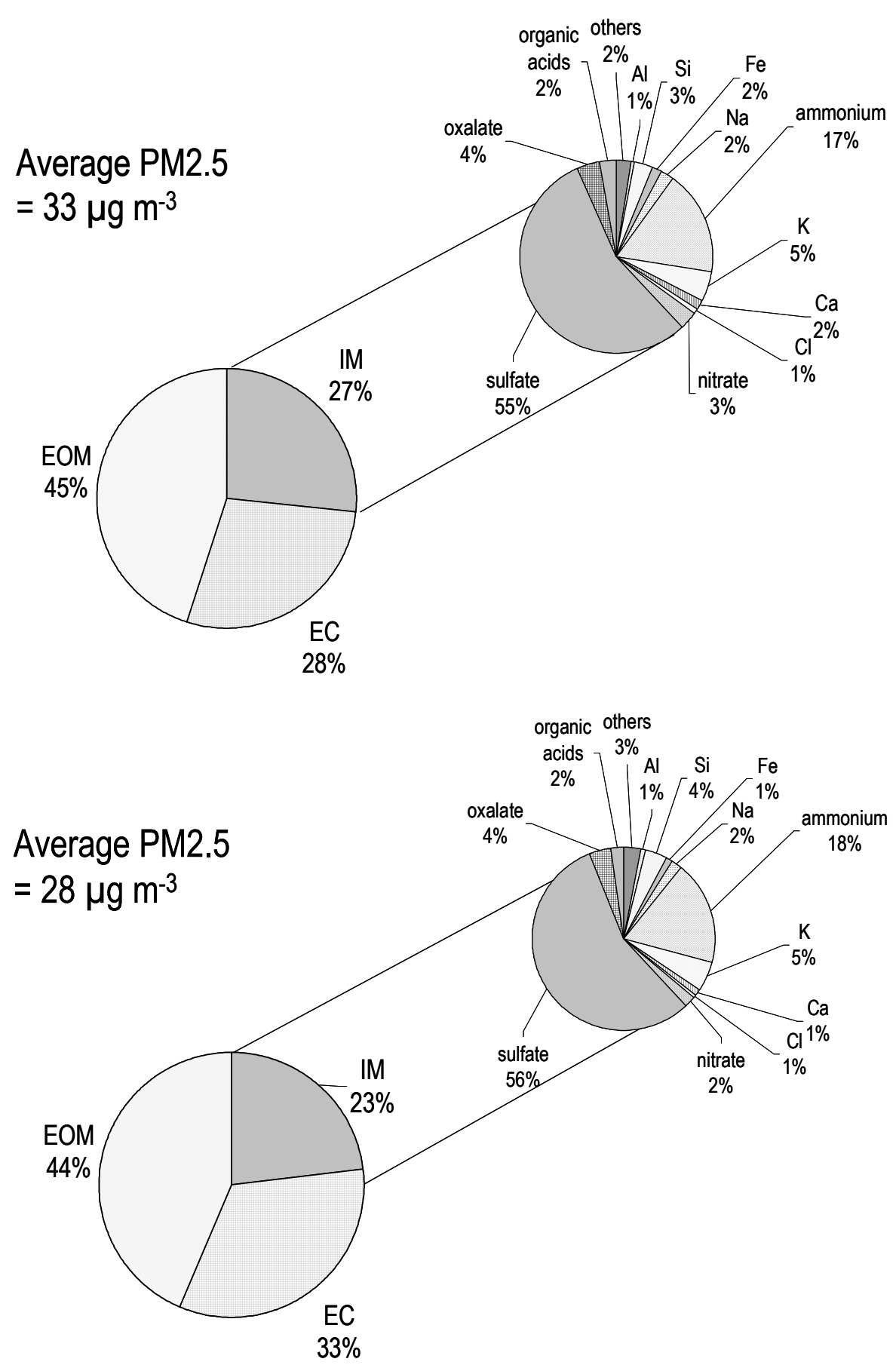

Fig. 8. Average chemical composition at Petaling Jaya (a) and at Gombak (b). "Organic acids" are formic acid and acetic acid. "Others" are $\mathrm{Br}^{-}, \mathrm{NO}_{2}^{-}, \mathrm{PO}_{4}^{3-}, \mathrm{F}^{-}$, methanesulfonic acid (MSA), Ti, V, Cr, $\mathrm{Mn}, \mathrm{Cu}, \mathrm{Co}, \mathrm{Ni}, \mathrm{Zn}$ and $\mathrm{Pb}$.

determined by changes in wind flow patterns, rather than temperature changes. The climate of Malaysia is characterised by uniform high temperatures, high humidity and high rainfall. Wind speed is a relevant meteorological parameter in terms of haze development as it affects ventilation (dilution) rates in an airshed.
Cumulative frequencies of daily mean Bsp at each site for each season of 1999 are shown in Fig. 9. At each site, during the southwest monsoon, the frequency distributions show a clear trend to larger Bsp and a larger range in Bsp values. During the other three seasons the frequency distributions display steeper slopes and a consistent, smaller range in Bsp. 
Table 4. Percentage of Bsp greater than $150 \mathrm{Mm}^{-1}$, mean Bsp and standard deviation $\left(\mu \mathrm{g} \mathrm{m}^{-3}\right)$ for each season at each site. Season abbreviations are defined in Table 3

\begin{tabular}{lcccccc}
\hline SEASON & \multicolumn{3}{c}{ PETALING JAYA } & \multicolumn{3}{c}{ GOMBAK } \\
& $\%>150 \mathrm{Mm}^{-1}$ & mean & stdev & $\%>150 \mathrm{Mm}^{-1}$ & mean stdev \\
\hline NE 1998 & $1 \%$ & 61 & 35 & $4 \%$ & 63 & 39 \\
Int1 1999 & $1 \%$ & 60 & 33 & $10 \%$ & 82 & 53 \\
SW 1999 & $14 \%$ & 97 & 64 & $19 \%$ & 115 & 79 \\
Int2 1999 & $2 \%$ & 63 & 35 & $4 \%$ & 68 & 42 \\
NE 1999 & $1 \%$ & 61 & 31 & $2 \%$ & 61 & 35 \\
Int1 2000 & $2 \%$ & 64 & 35 & $3 \%$ & 62 & 33 \\
SW 2000 & $14 \%$ & 101 & 81 & $17 \%$ & 103 & 67 \\
Int2 2000 & $1 \%$ & 62 & 32 & $3 \%$ & 61 & 38 \\
NE 2000 & $1 \%$ & 69 & 32 & $2 \%$ & 63 & 38 \\
\hline
\end{tabular}
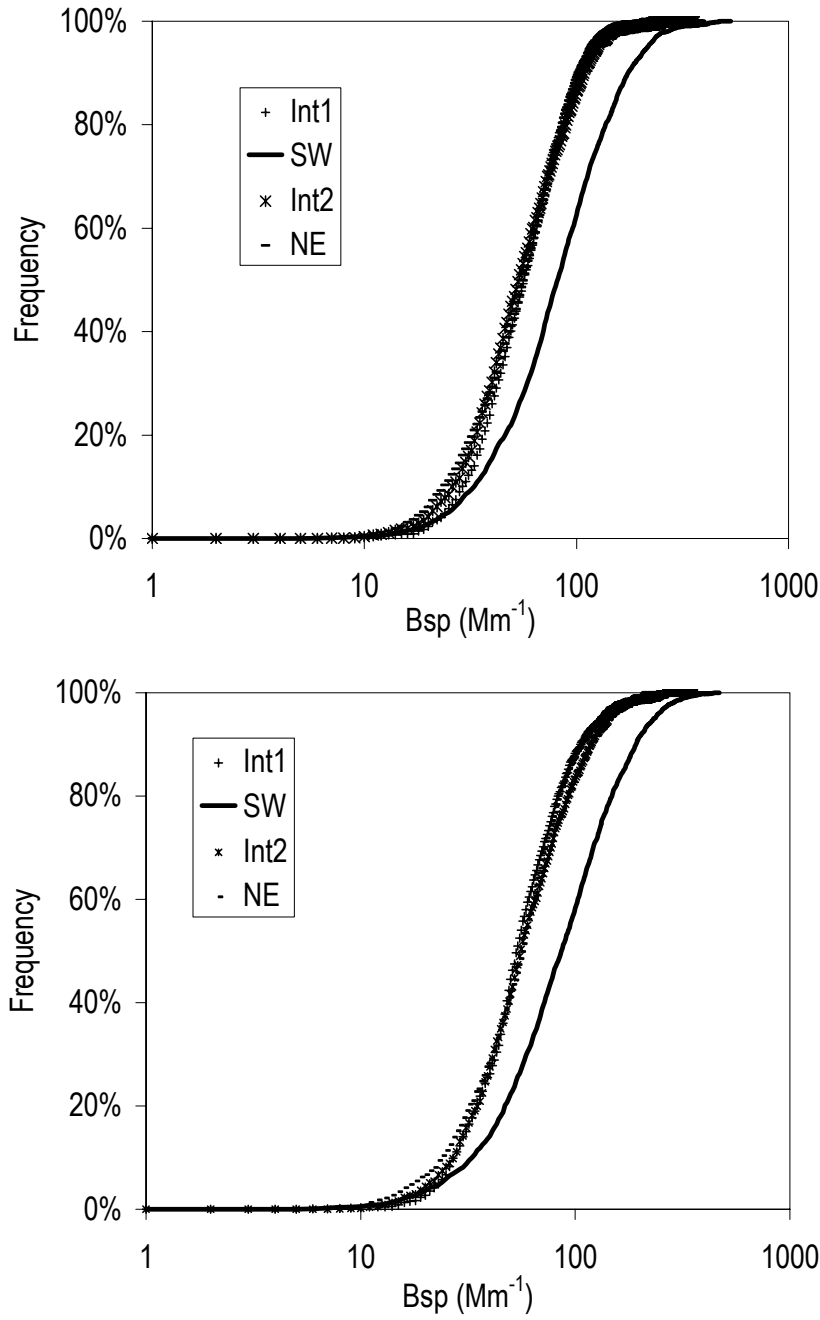

Fig. 9. Cummulative frequency of Bsp for different seasons in 1999 at Petaling Jaya and Gombak. The seasons Int1, SW, Int 2 and NE are defined in Table 3.
The same pattern was observed at both sites for 2000. During the southwest monsoon there is evidently an increased frequency of high Bsp values compared with the other seasons. At Petaling Jaya, as detailed in Table 4, during the southwest monsoon of each year approximately $86 \%$ of the data fall below the $150 \mathrm{Mm}^{-1}$ excessive haze threshold for 24-hour average Bsp. During the other seasons, this value is closer to $100 \%$. Similarly, at Gombak, approximately $80 \%$ of the data fall below $150 \mathrm{Mm}^{-1}$.

Figure 10 displays the number of fires on the islands of Sumatra, Kalimantan and Peninsular Malaysia for the period of December 1998 to December 2000. The data for these plots were compiled using satellite records from the Vietnam, Thailand and Darwin nodes of the World Fire Web. Also shown on the plot are the time periods for each season. There appears to be a coincidence between fires on Sumatra and the southwest monsoon periods for both years

Figure 11a shows the average Bsp as a function of surface $(10 \mathrm{~m})$ wind direction at Petaling Jaya for all of the data. The wind directions were modelled using the meteorological component of TAPM. This plot indicates that wind direction from the southwest corresponded with elevated scattering. In Fig. 11b, which shows the average number of fires for each wind direction, it is evident that the number of fires is greatest in the southwest direction from Kuala Lumpur, ie. on the island of Sumatra. However the satellite observations do also reveal consistently the occurrence of a smaller number of fires on Peninsular Malaysia.

In order to investigate the effect on Bsp levels in the Klang Valley caused by fires on Sumatra, Kalimantan and Peninsular Malaysia, data were extracted from the daily data set according to the following criteria:

1. Wind direction was from 150 to 300 degrees and the number of fires on Sumatra and Peninsular Malaysia was greater than 0 .

2. Wind direction was from between 90 and 130 degrees and the number of fires on the island of Kalimantan was greater than 0 . 


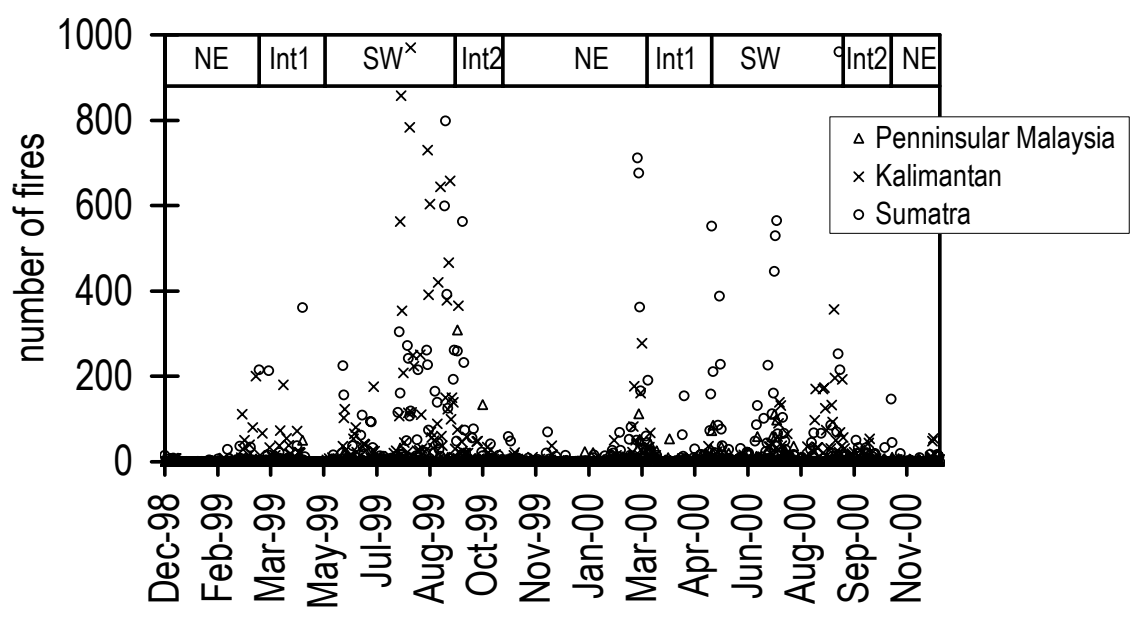

Fig. 10. Number of fires on Sumatra, Peninsular Malaysia and Kalimantan for each day between December 1998 and December 2000. Data were derived from fire maps obtained from three nodes of the World Fire Web operated by: Asian Institute of Technology in Thailand, Centre Interministeriel d'Applications Spatiales in Vietnam, and the CSIRO Earth Observation Centre in Australia. The World Fire Web is an activity of the European Commission Joint Research Centre in Italy.
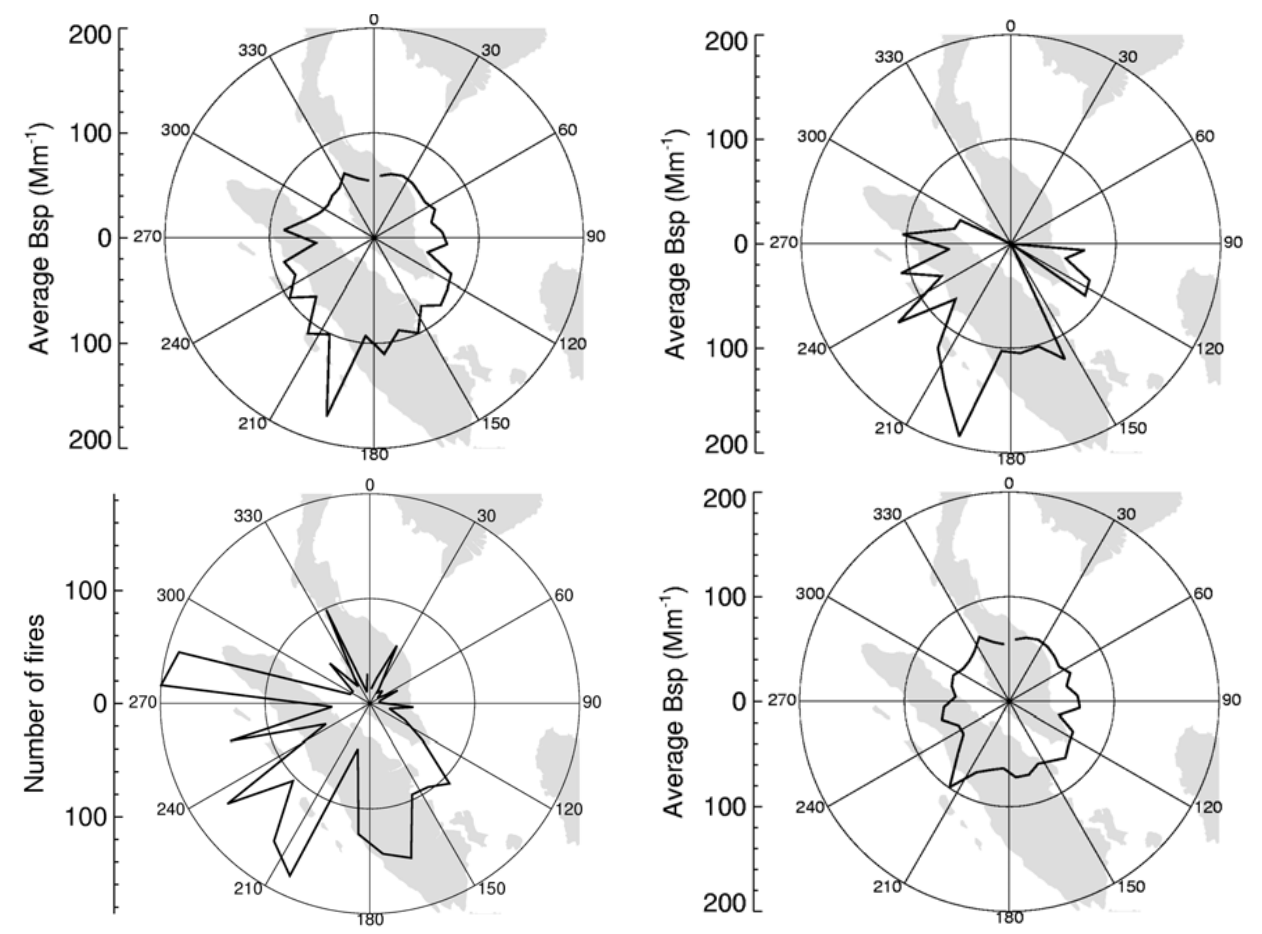

Fig. 11. (a) 24-hour average Bsp as a function of surface wind direction at Petaling Jaya. (b) Average number of fires as a function of surface wind direction at Petaling Jaya. Source of data is the same as for Fig. 9. (c) 24-hour average Bsp as a function of surface wind direction at Petaling Jaya during days likely to have been affected by fires from Sumatra, Kalimantan or Peninsular Malaysia. (d) 24-hour average Bsp as a function of surface wind direction at Petaling Jaya during days not likely to have been affected by fires from Sumatra, Kalimantan or Peninsular Malaysia.

The extracted data set (days more likely to be affected by fires) is shown in Fig. 11c; the remaining data (days less likely to be affected by fires) are shown in Fig. 11d. On days most likely to be affected by fires, the highest average 24-hour Bsp concentrations predominantly occur when the wind is from the southwest direction (Fig. 11c). However, on days less likely to be affected by fires the average 24hour Bsp concentrations are lower and appear to be associated with all wind directions (Fig. 11d). 

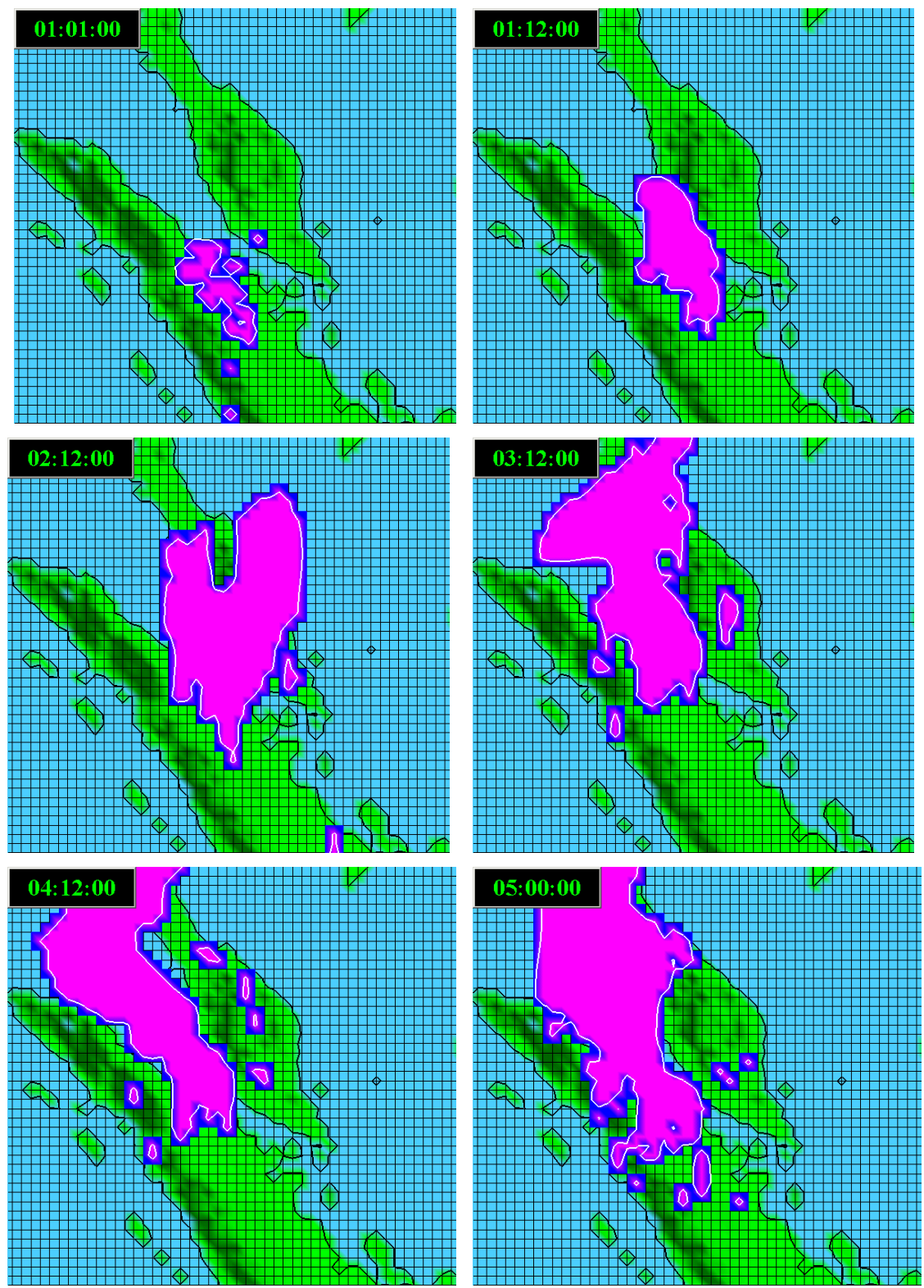

Fig. 12. Predicted dispersion of PM10 over Malaysia for the period of 10-13 July 2000. 04:02:00 represents day 4 hour 2.

Having removed the data for days when fires on the surrounding islands are likely to have affected Bsp in the Klang Valley, it is possible to reassess the seasonal variation in Bsp at Petaling Jaya and Gombak. Table 5 shows that during the southwest monsoon season of 1999, some elevation in aerosol scattering was observed at both sites; however, elevation in scattering was not evident during the southwest monsoon period of 2000. Indeed, the overall seasonal pattern is considerably more uniform in absolute Bsp levels and reduced variability (lower stdev) when effects of fires outside Malaysia are filtered out (Table 5), compared with the full dataset (Table 4). The greatest seasonal influence on exces- sive haze therefore appears to be related to the frequency of occurrence of fires throughout the Souteast Asian region, at times when atmospheric transport from source regions to the Klang Valley is favoured by seasonal wind patterns. In particular, transport of smoke from Sumatra during the southwest monsoon appears to be an important seasonal contributor to haze in the Klang Valley.

Atmospheric transport modelling using the CSIRO model TAPM, supports this conclusion. The model was run in a case study mode to seek confirmation of a cross-border influx of aerosol particles (modelled as PM10) into the Klang Valley region during a period of four days. The period for the 
Table 5. Mean Bsp and standard deviation $\left(\mathrm{Mm}^{-1}\right)$ for each season at each site for days not affected by fires on Sumatra, Kalimantan and Peninsular Malaysia. Season abbreviations are defined in Table 3

\begin{tabular}{ccccc}
\hline SEASON & \multicolumn{2}{c}{ PETALING JAYA } & \multicolumn{2}{c}{ GOMBAK } \\
& mean & stdev & mean & stdev \\
\hline NE 1998 & 60 & 25 & 63 & 31 \\
Int1 1999 & 60 & 24 & 82 & 42 \\
SW 1999 & 72 & 23 & 93 & 35 \\
Int2 1999 & 61 & 23 & 67 & 25 \\
NE 1999 & 61 & 20 & 61 & 25 \\
Int1 2000 & 63 & 17 & 62 & 22 \\
SW 2000 & 62 & 15 & 69 & 22 \\
Int2 2000 & 58 & 20 & 54 & 31 \\
NE 2000 & 68 & 21 & 62 & 24 \\
\hline
\end{tabular}

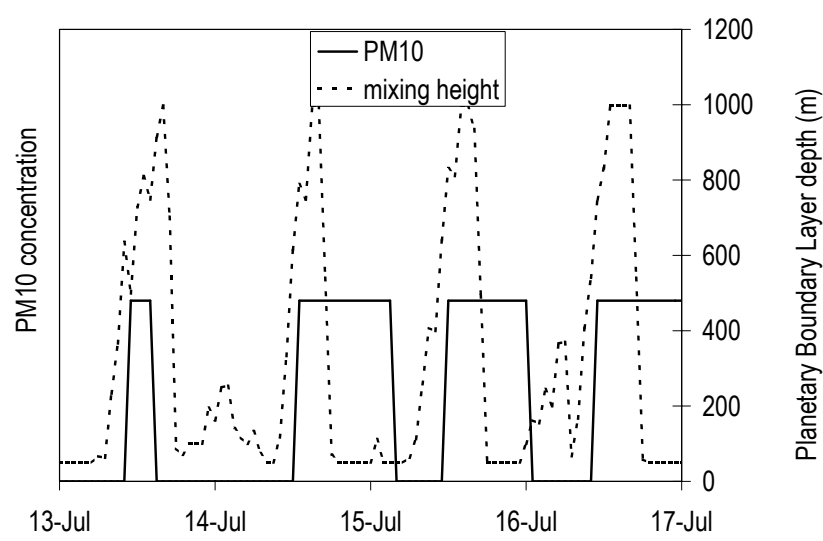

Fig. 13. PM10 and mixing height simulations at Petaling Jaya for 13 to 17 July 2000, where the only source of particles modelled is from 10 hotspots located on Sumatra emitting smoke at $1500 \mathrm{~m}$ (i.e. simulating the influx of smoke from aloft). PM10 units are arbitrary.

model study was chosen to be representative of periods in the southwest monsoon in which fires had been documented in Sumatra by satellite observations. For this particular case study simulation the period 10-13 July 2000 was chosen, a period midway through the southwest monsoon period for which fires were evident in Sumatra.

For the simulation, all particle emission sources other than fires in Sumatra and peninsular Malaysia were set to zero. "Hotspot" information was provided by the Malaysian Department of Environment and derived from the AVHRR infrared Channel 3 of the NOAA12/14 satellite. The majority of regional hotspots in the chosen period (over 90\%) were on Sumatra, although it is noteworthy that there were a few persistent hotspots in Malaysia as well.

The hotspots for 10-13 July 2000 were specified on the outer TAPM grid and an arbitrary emission of PM10 was assigned to each fire. Because the source strengths of the fires were unknown, absolute PM10 levels were not modelled. Instead, the transport and dilution patterns of smoke from the fires were simulated. The emission at each TAPM grid square was designated to be proportional to the number of fires mapped into that particular grid point. The duration of the fires was unknown, so each fire was assumed to last for the full 24 hours of the day on which the fire was observed.

The flow of PM10 for the specified fires over KL during the four modelled days is shown in Fig. 12. The time index in the upper left hand corner indicates day, hour, minute: thus 01:01.00 means day one, first hour after midnight local time, in this case 10 July 200001.00 . Note that the concentration contours are enhanced to show the plume movements more clearly; however, the predicted concentrations have no absolute significance because neither the emission strength, nor duration of fires was accurately known. The first panel shows the location of the fires at the start of the model run.

As time progresses on the first two days, a plume drifts towards Peninsula Malaysia with the prevailing southerly air flow, demonstrating that fires on Sumatra do affect KL. On the last two days, the northern part of Malaysia rather than the Klang Valley was affected by smoke from the Sumatran fires. At the same time a few persistent hotspots in Malaysia affected the Klang Valley, and the wind direction shifted from the southwest to the southeast, so that the central peninsular region was affected by the hotspots in southern Malaysia. This demonstrates that Malaysia itself will act as a source of smoke-enhanced haze if fires remain active on the peninsular.

In summary, should similar fires exist at any other times with similar wind flow patterns, it follows that smoke emitted from fires on Sumatra or on other islands in Southeast Asia will augment any background source of PM10 and haze in the Klang Valley.

\subsection{Smoke Diurnal Patterns}

Smoke also contributes to the diurnal pattern of Bsp. Two generic diurnal patterns of haze are evident from the overall Bsp datasets at both sites in the Klang Valley region (Fig. 3). The less common diurnal pattern of haze occurred on days of high haze, and exhibited a persistent peak around midday. It is postulated that the mixing down of smoke present in the lower troposphere after the onset of convective mixing may produce this midday peak. This hypothesis was tested using TAPM, which was run excluding the surface PM10 sources in Malaysia while only including PM10 injected high into the lower troposphere. An arbitrary series of ten point sources was chosen on Sumatra due south of KL emitting particles at $1500 \mathrm{~m}$, thereby simulating particles present in the air well above the surface, lofted there by the buoyancy of the plumes from the fires.

Results are shown in Fig. 13. The particles present in the lower troposphere are responsible for enhanced modelled PM10 concentrations in KL during the middle of the day. 
The planetary boundary-layer depth (PBL) reaches values of $1100 \mathrm{~m}$ or more during the daytime. The PM10 concentration increase to detectable levels once the PBL depth exceeds 900-1100 m, allowing the mixing down from aloft of the PM10 plume derived from long-range transport.

\section{Conclusions}

This paper has presented an overview of the methodology and some results from the MHS, with a qualitative assessment of the sources of particles contributing to haze in the Klang Valley.

By investigating the time series of aerosol scattering coefficient and the relationships between marker chemical species determined from PM2.5 aerosol samples, we have shown that smoke is a major source of particles to the Klang Valley. Secondary photochemical production of particles appears to be a significant source at the two measurement sites of Petaling Jaya and Grombak at all times. Sea-salt and soil-dust make only a minor contribution to aerosol in the Klang Valley. (Note that these qualitative descriptions of the sources affecting particles in the Klang Valley will be quantified in further work. In particularly, source apportionment analysis will be used to identify all sources, including a vehicle emission source, and to determine the relative contribution of each of these sources to the haze in the Klang Valley.)

Periods of excessive haze are defined as 24-hour average Bsp concentration of greater than $150 \mathrm{Mm}^{-1}$. These occurred on a number of occasions, between May and September 1999, during May 2000, and between July and September 2000. These periods coincided with the southwest monsoon seasons and with the presence of forest fires on the island of Sumatra. Transport modelling simulated the transboundary movement of smoke from hotspot sites on the island of Sumatra and Peninsular Malaysia to the Klang Valley for one week during the 2000 southwest monsoon. This modelling suggested that Sumatra is a very strong candidate as a source region for smoke aerosol that impacts on the Klang Valley region, and more widely across Malaysia. In addition, fires on Peninsular Malaysia were found to impact on haze development in the Klang Valley.

Acknowledgements. The authors would like to thank staff from the Malaysian Meteorological Service, Malaysian Department of Environment, Alam Sekitar Malaysia and the Aerosol Team of CSIRO Atmospheric Research. Also thanks to Paul Krummel from CSIRO Atmospheric Research for his help with data analysis. We gratefully acknowledge AusAID for substantially funding the study.

\section{References}

Brook, J. R., Dann, T. F., and Burnett, R. T.: The relationship among TSP, PM10, PM2.5 and inorganic constituents of atmospheric particulate matter at multiple Canadian locations. Journal of the Air Waste Management Association 47, 2-19, 1997.
Findlayson-Pitts, B. J and Pitts, J. N. Jr.: Chemistry of the Upper and Lower Atmosphere. Academic Press, San Diego, pp. 969, 2000.

Cohen, D. D, Gras, J. L, Garton, D., Firestone, T. and Bailey, G. M.: Study of atmospheric particles and gases in the Jakarta region, Final Report, CSIRO and ANSTO., 150, 1997.

Gao, S., Hegg, D., Hobbs, P. V., Kirchtetter, T. W., Magi, B. and Sadilek, M.: Water-soluble organic components in aerosols associated with savanna fires in southern Africa: Identification, evolution and distribution. Journal of Geophysical Research, 108(D13), 8491, doi:10.1029/2002JD002324, 2003

Gras J. L.: The Perth Haze Study. Report to the Department of Environmental Protection of Western Australia, CSIRO, 1996.

Griffing G. W.: Relationships between the prevailing visibility, nephelometer scattering coefficient, and sunphotometer turbidity coefficient. Atmospheric Environment 14, 577-584, 1980.

Hurley, P. J.: The Air Pollution Model (TAPM) Version 1 :Technical Description and Examples. CSIRO Atmospheric Research Technical Report, 1999.

JICA: Air quality management study for Kelang Valley Region, Final Report Vol.2 Main Report by Japan International Cooperation Agency, 1993.

Koe, L. C. C, Arellano, A. F, and McGregor, J. L.: Investigating the haze transport from 1997 biomass burning in Southeast Asia: its impact on Singapore. Atmospheric Environment 35, 2723-2734, 2001.

Lin C. I., Baker, M. and Charlson, R. C.: Absorption coefficient of atmospheric particles Applied Optics 12, 1357-1363, 1973.

Manins, P. C.: New measurement and modelling work on dry deposition, Proc. International Workshop on the Regional Air Quality Problems, 29 August 1994, Atmospheric and Environmental Research Institute, Seoul National University, Seoul, Korea. 27-34, 1994.

Mason, C. B and Moore, B: Principles of Geochemistry 4th edition, Wiley, New York, 1982.

McDonald, W. F.: Atlas of climatic charts of the oceans, Government Printing, Washington, 1938.

Millero F. T.: Physical chemistry of seawater, Annual Reviews in Earth and Planetary Science 2, 101-150, 1974.

MMS: Climate Summary Annual Report, Report by Malaysian Meteorological Service, 1999.

Muraleedharan, T. R., Rajojevic, M., Waugh, A., and Caruana, A.: Chemical characteristics of haze in Brunei Darussalam during the 1998 episode. Atmospheric Environment 34, 2725-2731, 2000.

NERI: The origin, formation and composition of aerosol haze in Malaysia. Report by the National Environmental Research Institute, 1998.

Radojevic, M. and Hassan, H.: Air quality in Brunei Darussalam during the 1998 haze episode. Atmospheric Environment 33, 3561-3568, 1999.

Seinfeld, J. and Pandis S.: Atmospheric Chemistry and Physics, John Wiley and Sons, Inc, New York, 1326, 1998.

USEPA: Quality Assurance Handbook for Air Pollution Measurement Systems, Volume V: Precipitation Measurement Systems (Interim Edition), Research Triangle Park, N.C., 180, 1994.

Vedal, S.: Ambient particles and health: the lines that divide, Journal of the Air and Waste Management Association, 47, 551-581, 1997. 